\title{
Reduction of Heat Losses from Greenhouses by Means of Internal Blinds with Low Thermal Emissivity
}

\author{
J. MEIJER*
}

\begin{abstract}
Heat losses in greenhouses may be substantially reduced by the use of heat reflecting blinds. Quantitative results are obtained solving a mathematical heat flow model by numerical methods. Special attention has been given to the emissivity and transmittance of the screen and the ventilation through screen and glass. The heat losses by condensation are obtained from a simultaneously solved moisture balance. In most cases condensation on the lower side of the screen influences the emissivity. An unexpectedly large part of the heat is transmitted by ventilation. The emissivity of the coated surface has been measured for a number of screen materials. The durability of the coatings is also taken into consideration. For greenhouse application it is always necessary to protect against corrosion.
\end{abstract}

\section{Introduction}

Because of sharp increases in the price of energy, fuel costs are a dominant aspect of glasshouse horticulture. One possible way to reduce the fuel consumption is through the use of thermal screens as heat reflecting covers over crop and heating system. In greenhouses, screens are already used for different purposes. Some blinds are opaque and are used for crops requiring photoperiod control. This type is often used by year-round chrysanthemum growers. There are also many screens to reduce sunlight, when it is very strong. Both types of screens can be used as thermal screens, but only at night, because in winter, when the light is reduced, all types of screens, even the transparent screens, have to be removed during the day. In this case it can be worthwhile to use screens with metal-coated surfaces. In the case of metal surfaces a low emissivity is accompanied by a high reflectance for heat radiation; in this way heat radiation from below is reflected by the screen while above the screen radiation to the cold windows is reduced.

To gain an insight into the savings that may be expected from the use of thermal screens, a computer model has been developed from which the influence of all parameters can be determined.

\section{The heat-flow model}

For the model the glasshouse complex is assumed to be large so that in comparison with the roof area, the wall area is insignificant and may be neglected. The screen is assumed to be horizontal below the gutters, as shown in Fig. 1, so the area of the unfolded screen is equal to the ground area. The inclined glass area is assumed to be greater by a factor $1 \cdot 1$. The conduction resistances of glazing bars and gutters have been taken to be the same as that of the glass in view of the small values compared with the local overall resistances. The independent heat-flows $Q$ are shown in Fig. 2, these heat fluxes being distinguished by radiation $\left(Q_{1}, Q_{5}, Q_{8}\right.$ and $\left.Q_{11}\right)$, convection $\left(Q_{4}\right.$ and $\left.Q_{10}\right)$, convection and condensation $\left(Q_{2}\right.$ and $\left.Q_{6}\right)$ ventilation $\left(Q_{3}\right.$ and $\left.Q_{7}\right)$ and conduction $\left(Q_{9}\right)$. The conduction resistance of the screen can be neglected. Also absorption of radiation by the inside air is not of interest due to the short distances involved. The heat-transfer coefficient $\alpha$ is defined from $Q=\alpha . \Delta T$. Using the heat resistances $R-1 / \alpha$ the figure can be simplified to the network scheme of Fig. 2(b).

\footnotetext{
- Twente University of Technology, Enschede, The Netherlands

Received 10 July 1979; accepted in revised form 10 May 1980
} 


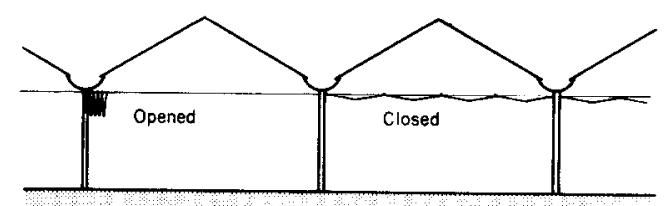

Fig. 1. The movable screens are hung on horizontal, stretched support wires. Opened screens should be compactly folded in the shadow of the gutters

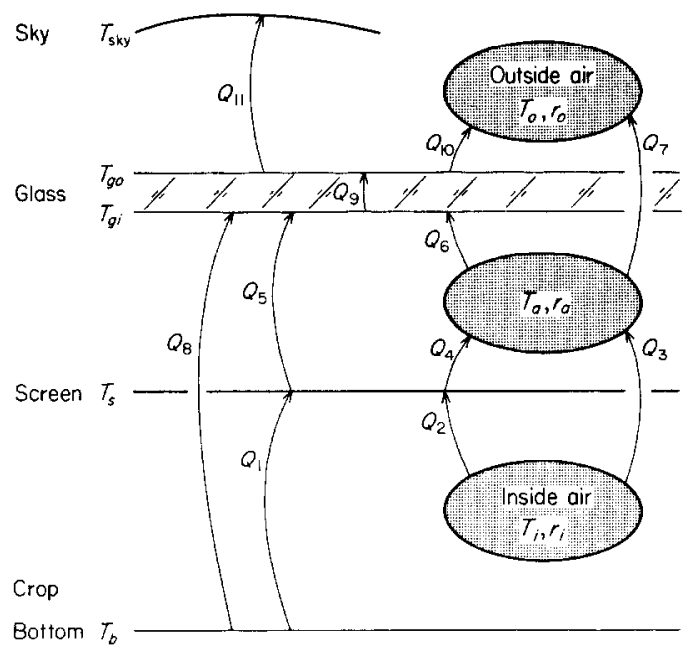

(a)

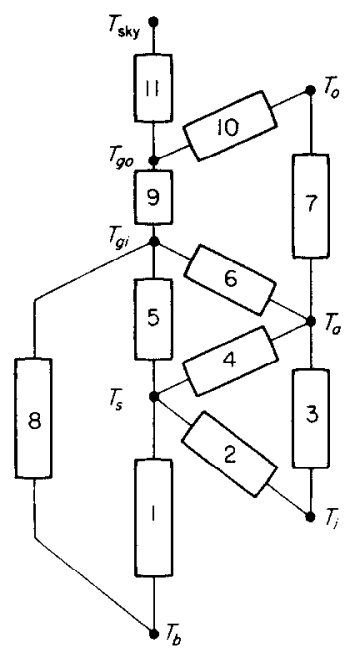

(b)

Fig. 2. Model of heat transfer in a greenhouse. (a) Independent heat flows $Q$. (b) Network scheme with heat resistances $R$

Some screen materials transmit infrared radiation. In such cases the transmission coefficient $\tau$ is taken into account, using Eqns (A2)-(A4) (Appendix A), which are similar to the equations developed by Amsen. ${ }^{1}$ In the latter case the flows 1 and 8 are taken together, making it difficult to solve for the temperature $T_{s}$. All area ratios have been incorporated in the heat resistances $R$, which are defined per $\mathrm{m}^{2}$ ground area. From Fig. $l$ it follows:

$\begin{array}{llrl}Q_{1} \cdot R_{1}=T_{b}-T_{s} & Q_{6} \cdot R_{6}=T_{a}-T_{g i} & Q_{11} \cdot R_{11}=T_{g o}-T_{s k y} \\ Q_{2} \cdot R_{2}=T_{i}-T_{s} & Q_{7} \cdot R_{7}=T_{a}-T_{o} & Q_{1}+Q_{2}-Q_{4}-Q_{5}=0 \\ Q_{3} \cdot R_{3}=T_{i}-T_{a} & Q_{8} \cdot R_{8}=T_{b}-T_{g i} & Q_{3}+Q_{4}-Q_{6}-Q_{7}=0 \\ Q_{4} \cdot R_{4}=T_{s}-T_{a} & Q_{9} \cdot R_{9}=T_{g i}-T_{g o} & Q_{5}+Q_{6}+Q_{8}-Q_{9}=0 \\ Q_{5} \cdot R_{5}=T_{s}-T_{g i} & Q_{10} \cdot R_{10}=T_{g o}-T_{o} & Q_{9}-Q_{11}-Q_{10}=0 .\end{array}$

From this set of 15 linear equations the unknown fluxes and temperatures can be solved. Writing them in matrix form we obtain a symmetric coefficients matrix, which can be easily solved.

Up to now the values of $\alpha$ and $R$ are considered to be constant. In reality they will be functions of such parameters as temperature and humidity as shown in Appendix A. Therefore the computation may be commenced with estimated values of the temperatures and the other variables from which the values of $\alpha$ are calculated. The solution gives an improved set of variables after which the process is started again. After a few iterations a stable solution is obtained.

A problem in the analysis is the unknown humidity $r_{a}$ of the air between screen and glass. This value is obtained from a moisture balance which contains the in- and outgoing streams of water by ventilation through screen and glass, and the condensation on the glass-surface. The last term 


\section{LIST OF NOTATION}

\begin{tabular}{|c|c|c|}
\hline \multicolumn{2}{|c|}{ Symbols } & Suffixes \\
\hline$A$ & area & a air, above \\
\hline$B$ & constant & bottom, below \\
\hline$C$ & constant & convection \\
\hline$L$ & heat of vaporization, length & condensation \\
\hline$Q$ & heat flow (absolute) & glass \\
\hline$\widetilde{R}$ & heat resistance & inside \\
\hline$T$ & temperature & outside \\
\hline$\Delta T$ & temperature difference & $r \quad$ radiation \\
\hline$U$ & total thermal transmittance & ref reference value (no screens) \\
\hline c. & specific heat & $s \quad$ screen, surface \\
\hline$h$ & relative humidity & topside \\
\hline$p$ & pressure (partial) & ventilation \\
\hline$r$ & coefficient of reflectance & water \\
\hline$v$ & ventilation rate & mean value over $24-\mathrm{h}$ \\
\hline$w$ & windspeed & \\
\hline$a$ & coefficient of heat transfer & \\
\hline$\varepsilon$ & emissivity & \\
\hline$p$ & specific mass & \\
\hline$\tau$ & coefficient of transmission & \\
\hline$\varphi$ & heat flow (relative) & \\
\hline$\sigma$ & Stephan Boltzmann's constant & \\
\hline
\end{tabular}

is strongly dependent on the humidity $r_{a}$ and the temperature difference $T_{a}-T_{g i}$ between the air and glass. This can make the process unstable, causing the computed humidity to oscillate. The magnitude of the error is estimated from the amplitude of the oscillation and this is taken into account in order to stabilize the process. The total iterative process is stopped if all differences (in temperatures and humidities) are less than 0.01 . This needs about 5 steps.

In addition to the case with one screen as shown in Fig. 2, the computations have also been performed for a double screen. In the latter case, there are 22 unknowns instead of 15 . The speed of convergence is comparable with the first case.

The computations are carried out for a stationary case, simulating a mean Dutch winter night. ${ }^{2}$ The assumptions are:

$\begin{array}{lrl}\text { Temperature inside air } & 17^{\circ} \mathrm{C} & \text { Relative humidity (inside without screen) } 80 \% \\ \text { Temperature outside air } & 3^{\circ} \mathrm{C} & \text { Relative humidity (inside below screen) } 90 \% \\ \text { Temperature sky } & -2^{\circ} \mathrm{C} & \text { Relative humidity (outside) } \\ \text { Windspeed } & 4 \mathrm{~m} / \mathrm{s} . & \end{array}$

The values of inside humidities have been based on unpublished results of measurements during the night.

Each calculation is commenced with the computation of the heat loss of a glasshouse without screen. This value $Q_{\text {ref }}$ is not constant, but depends on the external conditions. Then, for the same conditions, the heat-loss $Q$ of a glasshouse with a screen is computed. As a result only the relative heat loss $\varphi=Q / Q_{\text {ref }}$ is given. Although $Q$ as well as $Q_{\text {ref }}$ vary with the external conditions, it is found that $\varphi$ is only a very weak function of these conditions. 


\section{Results of computations}

The heat consumption of a mean winter night is assumed to be $60 \%$ of that used over $24 \mathrm{~h}$. For the British South Coast, Dawson and Winspear ${ }^{3}$ calculated a heat demand at night of $57 \%$ of the total. This value is the average over a full year and takes into account differences in temperature and length of day and night, in wintertime when the nights are long, this value can rise to about $70 \%$. Only this fraction of energy can be reduced by using blinds. During daylight when the black-out is removed $Q=Q_{\text {ref }}$ holds (same losses, same solar radiation) so that $\varphi=1$. Moreover, the folded screens can give some shadow; depending on the nature of the crop this can cause production losses of $3-5 \%$. This effect has not been taken into account.

The 24-h mean heat consumption now follows from

$$
Q_{24}=0.6 Q+0 \cdot 4 Q_{\text {ref }},
$$

so that

$$
\varphi_{24}=0.6 \varphi+0.4
$$

The computed values of $\varphi$ are given in Fig. 3 .

The rate of ventilation $v$ is defined as the rate of air exchange per unit of ground area $\left(\mathrm{m}^{3} / \mathrm{m}^{2} \mathrm{~s}\right)$ Note that a ventilation rate of $10^{-3} \mathrm{~m}^{3} / \mathrm{m}^{2} \mathrm{~s}$ or $1 \mathrm{~mm} / \mathrm{s}$ corresponds with about one change per hour.

In the reference case without the screen, the calculated heat losses are found as $Q_{\text {ref }}=151$ $\mathrm{W} / \mathrm{m}^{2}$ with a condensation rate of $48 \mathrm{~g} / \mathrm{m}^{2} \mathrm{~h}$. A value often used in practice is the total thermal transmittance; the $U$-value. In this case the value $U=10 \cdot 1 \mathrm{~W} / \mathrm{m}^{2} \mathrm{~K}$ is obtained. De Lint ${ }^{4}$ mentions that for large greenhouses under Dutch conditions, $U=9 \cdot 3-10 \cdot 5 \mathrm{~W} / \mathrm{m}^{2} \mathrm{~K}$. Tantau ${ }^{5}$ measured on a model $U=10.18 \mathrm{~W} / \mathrm{m}^{2} \mathrm{~K}$. Winspear ${ }^{6}$ found from measurements during the $1972 /$ 73 winter season in commercial nursery at Sussex a value of $U=10 \cdot 26 \mathrm{~W} / \mathrm{m}^{2} \mathrm{~K}$ at $w=4 \mathrm{~m} / \mathrm{s}$ windspeed.

The relative heat requirement is given in Fig. 3. The situation of a screen with a constant emissivity of 0.8 on the lower surface and a variable $0<\varepsilon<1$. on the top surface is expressed with full lines. With moderate screen ventilation (e.g. $v_{s}=10^{-3} \mathrm{~m}^{3} / \mathrm{m}^{2} \mathrm{~s}$ ) and a coating with $\varepsilon=0 \cdot 15$, the value of $\varphi=0.33$. In this way the savings during the night amount to $67 \%$. For a 24 -h day Eqn (3) gives $\varphi_{24}=0.60$, so the total saving is $40 \%$. Without coating $(\varepsilon=0.8)$ the value $\varphi_{24}=$ 0.66 is obtained. The improvement ( 0.06 or $9 \%$ relatively) by the coating is not spectacular, but can be worthwhile.

A screen coated on both sides (broken lines in Fig. 3) gives only a small improvement because on the lower surface there is heat flow by condensation owing to the high humidity below the screen. As a matter of fact even this small improvement is not real, since a water film forms an

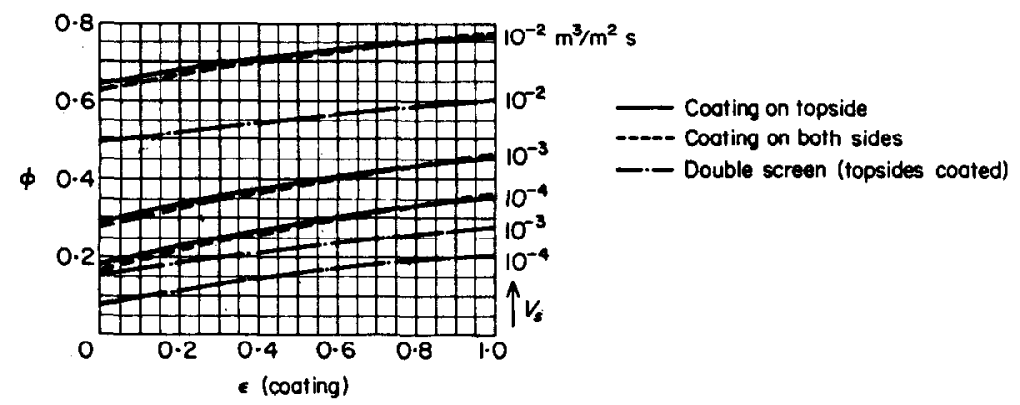

Fig. 3. Infuence of the emissivity $\varepsilon$ on the relative heat losses $\varphi$ for different screen surfaces and ventilation through the screen $\left(v_{s}\right)$. The emissivity of the uncoated surfaces is 0.8 and the ventilation rate through the glass $v_{g}=10^{-3} \mathrm{~m}^{3} / \mathrm{m}^{2} \mathrm{~s}$ 


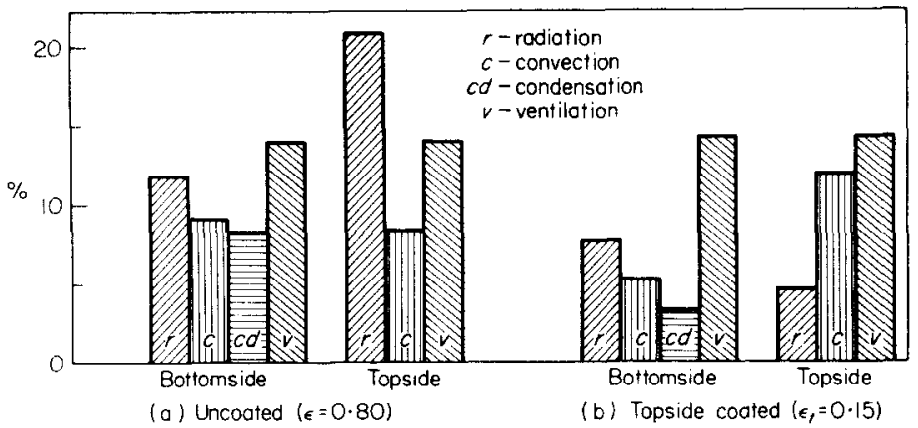

Fig. 4. Example of the different heat flows through the surfaces calculated for a ventilation of $10^{-3} \mathrm{~m}^{3} / \mathrm{m}^{2} \mathrm{~s}$ through the screen. Values are relative to the total losses in a glasshouse without screen

absorbing layer on the surface, eliminating the effect of the coating. A water layer of $0.01 \mathrm{~mm}$ absorbs already more than $80 \%$ of the infrared radiation. From the computations, the average condensation rate is about $15 \mathrm{~g} / \mathrm{m}^{2} \mathrm{~h}$. Only in a few cases with high ventilation rates does the screen remain dry. Water layers may be prevented by using a wax-like coating with a high surface tension, which causes the water to condensate in droplets covering only a small fraction of the screen area.

As mentioned, the computations have also been performed for a double screen, one on top of the other. The results of the simulation of these screens, only coated on the top side, are presented by the interrupted lines in Fig. 3.

An example of the contribution of the separate heat flows is given in Fig. 4. Through the uncoated screen the total flow amounts to $72 \mathrm{~W} / \mathrm{m}^{2}$ (a) and through the coated screen $52 \mathrm{~W} / \mathrm{m}^{2}$ (b). Note that as a result of the coating on the topside the radiation part is decreased strongly, but the contributions of convection and ventilation are increased. This is caused by the increased temperature differences (increased screen temperature $T_{s}$ and decreased air temperature $T_{a}$ ).

In practice many screens are used to protect the crop against sunburn. They have a good diffuse transmission for sunlight (about $50 \%$ ), which is attended with a considerable infrared transmission (e.g. 20\%). For other applications transparent materials will be used and these often show a considerable infrared transmission. For polyethylene values exceeding $50 \%$ were measured. Fig. 5 gives, for such such-like materials, the relative heat loss as a function of the infrared transmission $\tau$. If, for some crops, the reduction in light transmission is acceptable, this material can also be used during daytime. Then the savings shown are 24-h savings directly, but consequently there is a reduction of light. Bailey ${ }^{7}$ mentions a value of $14 \%$.

The effect of the ventilation rate is shown in Fig. 6. The curves have been computed for a screen with a coating on the top side with $\varepsilon=0 \cdot 15$. First (a) the ventilation through the glass $v_{g}$ is constant, while the ventilation through the screen $v_{s}$ is varied. Then (b) $v_{s}=$ constant while $v_{g}$ is varied. Here it must be understood that $\varphi$ is relative to a glasshouse without screens, but with the same value of $v_{g}$. Although the relative heatloss $\varphi$ falls by increasing $v_{g}$, the absolute losses $Q$ are rising. If both $v_{g}$ and $v_{s}$ increase then $\varphi$ will also increase (c). In real cases, with increasing wind speed, $v_{g}$ will be influenced much more than $v_{s}$ so $\varphi$ will be near to curve (b).

\section{Comparison with measured values}

Fig. 7 shows some values for $\varphi$ as found by Bailey and Winspear. ${ }^{-8}$ They measured the heat losses $Q$ in similar compartments with different blinds. The value $\varphi=Q / Q_{\text {ref }}$ is given at different measured windspeeds. 


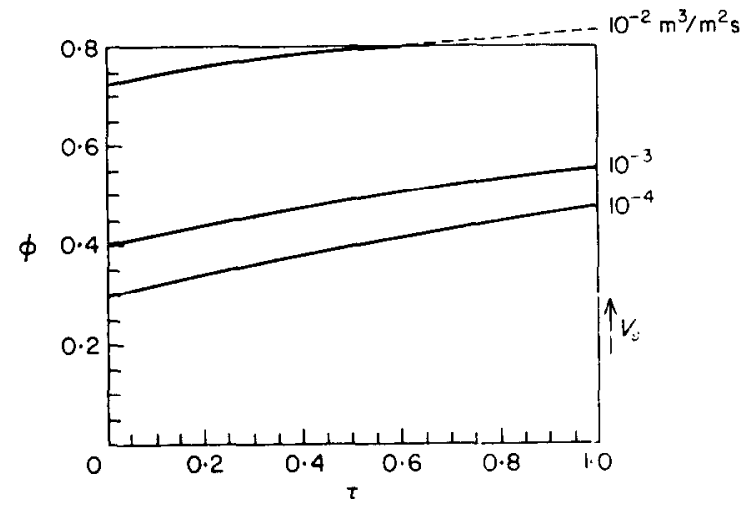

Fig. 5. Relative heat losses $\varphi$ as function of the infrared transmittance $\tau$ of the screen. Values have been calculated for $\varepsilon=0 \cdot 70(I-\tau)$ on both sides and $v_{g}=10^{-3} \mathrm{~m}^{3} / \mathrm{m}^{2} \mathrm{~s}$

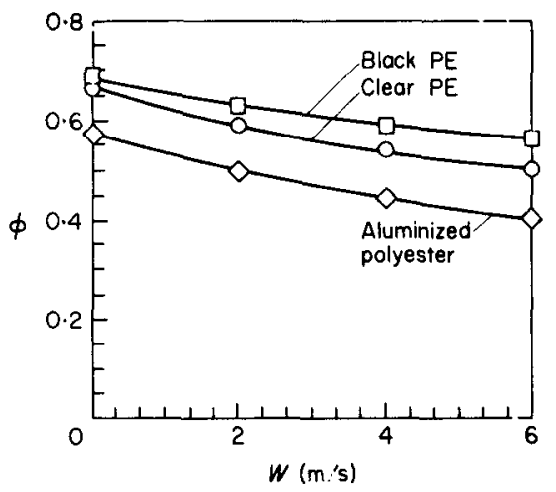

Fig. 7. Relative heat lossesas measured by Winspear ${ }^{6}$ as function of the outside windspeed $w$

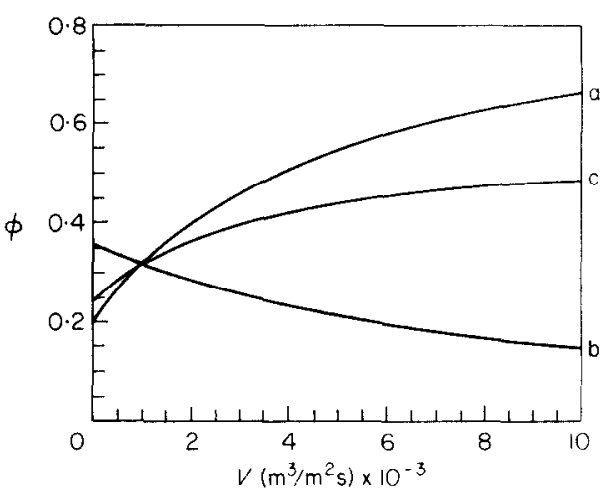

Fig. 6. Influence of the ventilation rate through the screen $(s)$ and glass $(g)$. Values have been calculated for a screen with protected aluminium coating on the topside $(\varepsilon=0.15, \tau=0)$.

(a) $v_{g}=$ constant $=10^{-3} \mathrm{~m}^{3} / \mathrm{m}^{2} s, v_{s}=v($ variable $)$.

(b) $v_{s}=$ constant $=10^{-3} \mathrm{~m}^{3} / \mathrm{m}^{2} \mathrm{~s}, v_{g}=v($ variable $)$.

(c) $v_{g}=v_{s}=v$ (both variable)

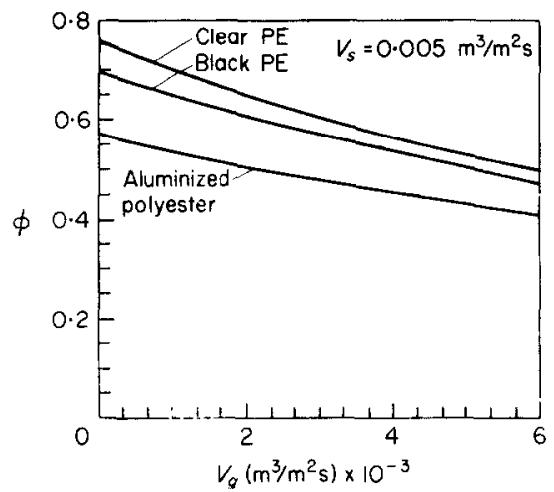

Fig. 8. Computed heat losses for the materials as shown in Fig. 7 calculated as function of the ventilation through the glass. The ventilation rate through the screen is put on $0.005 \mathrm{~m}^{3} / \mathrm{m}^{2} \mathrm{~s}$

A correlation between the ventilation rate through the glass and the windspeed seems evident. For this reason the values of $\varphi$ as function of $v_{g}$ (Fig. 8) were calculated for the materials used. As material constants the values given by Winspear ${ }^{6}$ were used and $\tau=0.5$ was assumed for the transparent polyethylene. Measurements by Heissner ${ }^{9}$ show a linear relation between ventilation rate and windspeed. Taking $v_{g}=10^{-3} w$ a very good correlation with the experiments was obtained for the aluminized polyester. In the case of polyethylene, the correlation is less significant. It is surprising that the measured heat losses with a black polyethylene blind are more than with a transparent one. The difference increases with increasing windspeed, so it seems there was less ventilation through the clear screen. As shown in Figs 3 and 5 this results in a displacement of the $\varphi$-lines.

Tantau $^{10}$ reports a high share of air exchange heat loss by using screens. His calculations show an increased humidity below the screen causing a reduced transpiration of the plants. In the present study, when screens are only used at night, this effect is not shown to be of high importance. 


\section{Testing materials with low emissivity}

The most important requirements for the screen materials are low emissivity and long life. To measure the total emissivity of the screen surfaces a precision instrument has been developed. It measures in a wavelength range from $0 \cdot 15$ to $50 \mu \mathrm{m}$ with an absolute error less than $0.3 \%$. By using this instrument the emissivity and transmittance of several materials have been measured. Most materials are aluminium-coated and in a few cases provided with a thin protective layer over the thin aluminium layer to protect against corrosion. Measurements were made before, during and after the following experiments:

1. Exposure in a small greenhouse (September 1976-July 1977);

2. Mechanical testing by 150,000 cycles winding;

3. High humidity and temperature $\left(98 \%, 25^{\circ} \mathrm{C}\right)$;

4. Condensation of water on the surface.

Based on experience with aluminium-coated mirrors damage of the pure aluminium-coating in a humid atmosphere was expected, but a thin glass-coating over the aluminized surface was thought to give a good protection.

First a spunbonded material of polyethylene fibres, Tyvec (Du Pont) was coated with aluminium and aluminium-glass layers. The measured emissivity of the uncoated material is $0 \cdot 7$, but with an aluminium coating values of $0 \cdot 10-0 \cdot 14$ depending on the thickness of the layer were obtained. With a thin glass-coating the emissivity increases (Fig. 9).

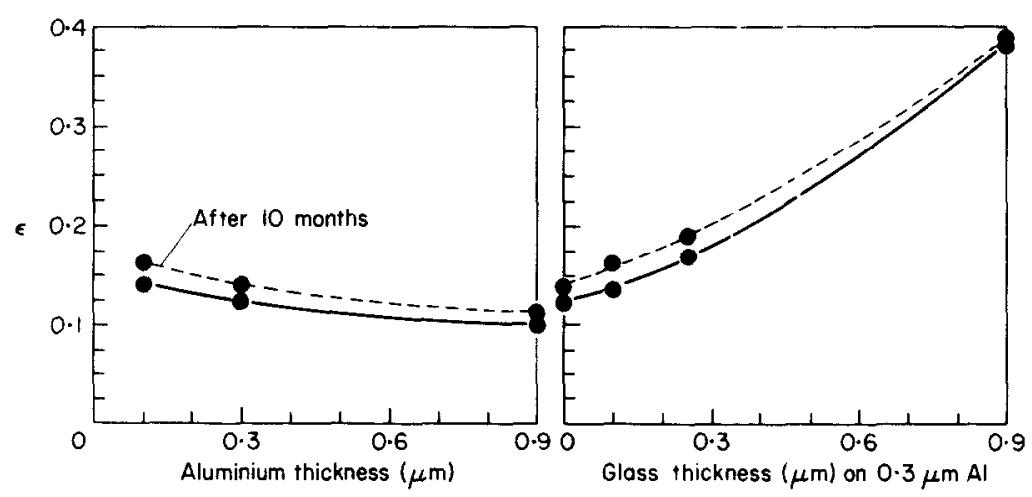

Fig. 9. Emissivity of aluminium and aluminium-glass coatings on a spunbonded olefin. Broken lines show results after 10 months in a small greenhouse

For good reflection and small absorption a minimum thickness is necessary. In the case of pure aluminum this is about $0.05 \mu \mathrm{m}$; then the theoretical emissivity amounts to 0.019 . The lowest value we measured for an aluminium foil was 0.018 . For aluminized surfaces, values of 0.029 on a smooth polyester film and up to 0.200 on rough fabrics were obtained. The higher emissivity is caused by impurities in the deposited layer and especially by the roughness of the surface enlarging the real area.

The samples of Fig. 9 have been exposed during a period of 10 months in a small greenhouse at the University and have been measured frequently. During this time the emissivity increased about 0.02 as shown by the broken lines in Fig. 9. The shects were hung vertically on a line and kept dry all the time. Other sheets were mechanically tested by winding up and down on a cylinder (diameter $30 \mathrm{~mm}$ ) with a load of $25 \mathrm{~N} / \mathrm{m}$. For most layers it was found that after 150,000 cycles the increase of the emissivity was less than 0.01 . 
With high humidity $(98 \%)$ it was noted that there was no significant change of emissivity after 3 weeks. When, by a fault in the set-up, condensation appeared, an unprotected aluminium layer on Tyvec was damaged in 2 days.

From that time the sheets were only tested by condensing water vapour at $35^{\circ} \mathrm{C}$ on the cool surface. With a protective glass layer $(0 \cdot 1 \mu \mathrm{m})$ the coating held for 40 days. Thicker layers gave a slight improvement up to 80 days. When using several plastic coatings on the aluminium-coated Tyvec the best held for 100 days.

Better results were obtained by using a vinyl-coating (Union Carbide type VMCH) on an aluminium-coated polyesterfilm. After 150 days of condensation no significant change could be measured. With this $2 \mu \mathrm{m}$ thick vinyl layer the emissivity is $0 \cdot 154$.

\section{Conclusions}

Using an opaque screen with a moderate ventilation rate the daily energy savings have been calculated to be $34 \%$. If, for heat radiation, the screen is $50 \%$ transparent, for example polyethylene, the savings will be $25 \%$. With a protected aluminium coating on the topside this value increases to $40 \%$.

The aluminium coating should be on the top side of the screen. When using screens, which are coated on both sides, the savings will increase by only $1 \%$. In addition to this, the heat reflecting under-side will increase the leaf temperature at constant air temperature, causing an additional saving of $2 \%$, providing that the screen remains dry.

The influence of the ventilation through the screen appears to be very high. Comparing calculated results with measurements it seems that the ventilation rates are high. For this reason it is worthwhile to develop screen systems with less air leakage.

From material tests it has been found that aluminium coatings are damaged by condensation on the surface. For this reason a protective coating over the thin aluminium layer is necessary. A protective coating decreases, however, the long wave reflectance of the surface.

$\mathrm{Up}$ to now aluminium-coated screens are rather expensive. From the economic point of view the life time should be 3 years or more. Therefore special attention should be paid to the motorized screen handling system, compact folding, prevention of water accumulation and easy maintenance.

\section{Acknowledgement}

I am very obliged to the initiator of this investigation, Prof. Dr. Ir. A. Nawijn, who was an inspiring source of new ideas during our regular and fruitful discussions.

\section{REFERENCES}

1 Amsen, M. G. The role of transparency on the radiant heat loss from the plant canopy in protected spaces. Acta hort., $197876271-274$

2 Schuurmans, C. J. E.; van den Dool, H. M. and Wisse, J. A. Luchtverontreiniging en wereldklimaat. Ingenieur, $197991265-274$ (in Dutch)

3 Dawson, J. R.; Winspear, K. W. The reduction of glasshouse heat losses by internal blinds. J. agric. Engng Res., 197621 431-438

4 Lint, P. J. A. L. de Toepassing van total energy in de glastuinbouw. Polytechn. tijdschr., 1979 E 34 (3) 142-147 (in Dutch)

5 Tantau, H. J. Der Einfluss von Einfach- und Doppelbedachungen auf das Klima und den Wärmehaushalt von Gewächshäusern. Gartenbautechn. Informationen, 41975117

6 Winspear, K. W. Thermal screens for glasshouse fuel saving. N.I.A.E. Paper No. 7, November 1976

T Bailey, B. J. Reducing glasshouse heat losses by internal blinds of different material. Dept. Note DN/G/ 617/2105. Natn. Inst. agric. Engng, Silsoe, August 1975 (unpubl.)

- Bailey, B. J.; Winspear, K. W. Reducing the heat requirements of a glasshouse. Acta hort., 197551 19-28 
' Heissner, A. Experimentelle Untersuchung des Luftaustausches von nicht gelüfteten Gewächshäusern. Arch. Gartenbau, $196715521-532$

1 Tantau, H. J. The influence of single and double shelters on the climate and heat consumption of gree'nhouses. Acta hort., $1978 \mathbf{8 7} 119-123$

1 Nawijn, A. Radiation transfer. Dept. Note WB.80/FT.5146. Techn. Univ. Twente 25 February 1980 (unpubl.)

12 Dubbel. Taschenbuch, 1974 1, 475

${ }^{13}$ Kanthak, P. Der Einfluß von Heizungssystemen auf das Klima. FortschrBer. VDI-Z. Reihe, 19706 (28)

\section{Appendix A}

Heat transfer coefficients

The heat transfer coefficients are defined as $\alpha=Q / \Delta T$.

Heat transfer by radiation

For the heat transfer from surface $A_{1}$ to $A_{2}$

$$
\alpha_{r}=\sigma \frac{\left(T_{1}^{2}+T_{2}^{2}\right) \cdot\left(T_{1}+T_{2}\right)}{\frac{1}{\varepsilon_{1}}+\frac{A_{1}}{A_{2}}\left(\frac{1}{\varepsilon_{2}}-1\right)} .
$$

With the glassroof (outside) as surface 1 and the sky as surface $2, A_{1}$ can be neglected with respect to $A_{2}$. In the special case of 3 planes from which the middle is partly transparent, as shown in Fig. 10, Nawijn" gives the following equations:

$$
\begin{gathered}
\alpha_{12}=\frac{\frac{1}{2} \sigma\left(T_{1}+T_{2}\right)^{3} \varepsilon_{1}\left[\varepsilon_{3} r_{4} \tau+\varepsilon_{2}\left(1-r_{3} r_{4}\right)\right]}{\left(1-r_{1} r_{2}\right)\left(1-r_{3} r_{4}\right)-\tau^{2} r_{1} r_{4}}, \\
\alpha_{34}=\frac{\frac{1}{2} \sigma\left(T_{3}+T_{4}\right)^{3} \varepsilon_{4}\left[\varepsilon_{2} r_{1} \tau+\varepsilon_{3}\left(1-r_{1} r_{2}\right)\right]}{\left(1-r_{1} r_{2}\right)\left(1-r_{3} r_{4}\right)-\tau^{2} r_{1} r_{4}}, \\
\alpha_{14}=\frac{\frac{1}{2} \sigma\left(T_{1}+T_{4}\right)^{3} \tau \varepsilon_{1} \varepsilon_{4}}{\left(1-r_{1} r_{2}\right)\left(1-r_{3} r_{4}\right)-\tau^{2} r_{1} r_{4}} .
\end{gathered}
$$

\section{Heat transfer by convection}

With this type of heat transfer there is conduction through a thin boundary layer which is determined by the flow pattern. Dubbel ${ }^{12}$ gives for natural convection on horizontal surfaces, when the heat flows upwards, which is the case inside the greenhouse:

$$
\alpha_{c}=2 \cdot 5 \Delta T^{l} \text {. }
$$

This equation can also be used for the inclined roof surfaces. In most other literature we find instead of the coefficient 2.5 lower values (1-3-2). These values are given for free convection in which disturbing influences of air movements are eliminated, which in practice will not be

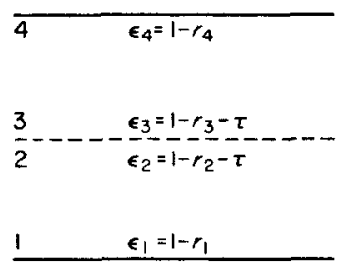

Fig. 10. Radiation transfer through a plane with transmittance $\tau$ 
the case. From dimensional analysis it follows for laminar free convection that $\alpha$ is proportional to $(\Delta T / L)^{\ddagger}$ or in the turbulent case to $\Delta T^{*}$. We follow the current practice to leave out the length dimension if $L>1 \mathrm{~m}$.

Outside the greenhouse there will be forced convection. Then the heat transfer is a function of the windspeed, Kanthak ${ }^{13}$ found:

$$
\alpha_{c}=3 \cdot 5 w
$$

\section{Heat transfer by condensation}

The moisture transport to a cool surface takes place by diffusion through a boundary layer. As by convection the thickness of this layer depends mainly on the flow conditions. So there follows a relation between $\alpha_{c}$ and $\alpha_{c d}$. A good approximation is

$$
\alpha_{c d}=\alpha_{c}\left[h \cdot \exp \left(-B / T_{a}\right)-\exp \left(-B / T_{s}\right)\right] . C / \Delta T .
$$

The constants $B$ and $C$ are for water vapour at $T \approx 290 \mathrm{~K} ; B=5345 \mathrm{~K}$ and $C=2 \cdot 8 \times 10^{-9} \mathrm{~K}$. If there is condensation $\left(\alpha_{c d}>0\right)$ both parallel heat streams are combined to one stream in the model. The partial pressure follows from the Clausius-Clapeyron equation

$$
p=h \cdot \exp (14 \cdot 5-B / T) \text { bar. }
$$

\section{Heat transfer by ventilation}

By ventilation there is an exchange of air and water vapour from below (b) to above (a) and the reverse through screen and glass. Assuming an enclosed space below the plane then the masstransport of air up- and downwards must be equal. Note that for the transport of water vapour through the screen there is no continuity. From this condition the coefficient of heat transport is found:

$$
\alpha_{v}=\frac{\Delta Q}{\Delta T}=v \cdot\left[\rho_{a i r} c_{a i r}\left(1-p_{b}\right)+\rho_{w} c_{w} p_{w}+\rho_{w} \frac{L}{\Delta T}\left(p_{b}-k p_{a}\right)\right]
$$

in which the constant $k=T_{a}\left(1-p_{b}\right) / T_{b},\left(1-p_{a}\right) \approx 0.96$ and $p_{a}$ and $p_{b}$ follow from Eqn (A8). The term $\rho_{w} c_{w} p_{w}$ can be neglected as it is typically $\sim 1 \%$. The specific heat $c_{a i r}$ is, because of the difference in partial air pressure over the screen, a little greater than the value at constant pressure, e.g. $c_{a i r}=1.08 c_{p}$. 